\title{
Fibrin sealant patches: powerful and easy-to-use hemostats
}

This article was published in the following Dove Press journal:

Open Access Surgery

18 September 2014

Number of times this article has been viewed

\section{William D Spotnitz}

Surgical Therapeutic Advancement Center (STAC), Department of Surgery, University of Virginia Health System, Charlottesville, VA, USA
Correspondence: William D Spotnitz Surgical Therapeutic Advancement Center (STAC), Department of Surgery, University of Virginia Health System, PO Box 80।370, Charlottesville, VA 22908-1370, USA

Email wspotnitz@virginia.edu

\begin{abstract}
Fibrin sealant liquid was approved for use in the US in 1998 by the Food and Drug Administration as the first of a new generation of hemostats, sealants, and adhesives. The initial fibrin sealant liquid use in the country was limited by obstacles in the formulation's ease of use (usability). Specifically, it was associated with cumbersome preparation, including thawing, mixing, and applicator loading. Although these challenges have been addressed to some extent, a new generation of fibrin sealants in the form of patches has been introduced, boasting significant efficacy as well as elimination of the liquid preparation complexities. Additionally, the patches may provide enhancements in efficacy because they are easily combined with manual pressure to arrest bleeding. In addition, usability has been increased because they may be stored at room temperature and they are provided in packages ready for immediate use. This review will highlight the capabilities of the two Food and Drug Administration-approved fibrin sealant patches and review the recent literature on fibrin sealant patch use.
\end{abstract}

Keywords: fibrin sealant, liquid, patches, hemostats, safety, efficacy, usability, cost

\section{Introduction}

The beginning of the modern era of hemostats, sealants, and adhesives was marked by the US Food and Drug Administration (FDA) approval of the first new hemostat, liquid fibrin sealant, in 1998. This new liquid, in combination with previously available materials, as well as more recently approved agents, provides a large number of products in three specific groups (hemostats, sealants, and adhesives) from which the surgeon can choose to enhance tissue management. A system for describing these agents using groups, categories, and classes has been published in order to help organize and understand the uses of these materials. ${ }^{1-4}$ For the purposes of classifying the new fibrin sealant patches, it is necessary to know the categories and classes that make up the hemostat group, as shown in Table 1. As can be seen, the fibrin sealants represent one of the four major categories of hemostats. The fibrin sealant patches (highlighted in bold) now represent two of the four classes of agents available within the category. The introduction of these fibrin sealant patches has enhanced both the efficacy and ease of use (usability) of this category of materials. These characteristics will be presented in detail in the following sections.

\section{Fibrin sealant formulations: liquids versus patches}

As can be seen in Table 1, the fibrin sealant category now consists of four classes of agents, which include five individual commercial products. Three products are in the fibrin sealant liquid classes. The other two products are the more recently 
Table I Available US Food and Drug Administration-approved hemostats in 2014, with fibrin sealant patches highlighted in bold

\begin{tabular}{|c|c|c|c|c|}
\hline Group & Category & Class & Brand & Manufacturer \\
\hline \multirow[t]{20}{*}{ Hemostats } & Mechanical & Porcine gelatin & Gelfoam Sponge and Powder & Pharmacia, Kalamazoo, MI, USA \\
\hline & & & Surgifoam Sponge and Powder & Ethicon/J\&J, Somerville, NJ, USA \\
\hline & & Bovine collagen & Avitene: Sheet, Flour, and & Davol/Bard, Warwick, RI, USA \\
\hline & & & Ultrafoam & Integra, Plainsboro, NJ, USA \\
\hline & & & Helistat, Helitene & Ethicon/J\&J, Somerville, NJ, USA \\
\hline & & & Instat, Instat $\mathrm{MCH}$ & \\
\hline & & Oxidized regenerated cellulose & $\begin{array}{l}\text { Surgicel: Sheet, Fibrillar, } \\
\text { Nu-Knit, and SNoW }\end{array}$ & Ethicon/J\&J, Somerville, NJ, USA \\
\hline & & Polysaccharide spheres & Arista & Medafor/Bard, Minneapolis, MN, USA \\
\hline & & & Vitasure & Stryker, Malvern, PA, USA \\
\hline & Active & Bovine thrombin & Thrombin JMI & Pfizer, New York, NY, USA \\
\hline & & Human pooled plasma thrombin with & Evithrom & Ethicon/J\&J, Somerville, NJ, USA \\
\hline & & porcine gelatin sponge or powder & Gelfoam Plus & Baxter, Hayward, CA, USA \\
\hline & & Recombinant human thrombin & Recothrom & Medicines Company, Parsippany, NJ, USA \\
\hline & Flowable & $\begin{array}{l}\text { Bovine gelatin and human pooled } \\
\text { plasma thrombin }\end{array}$ & Floseal & Baxter, Fremont, CA, USA \\
\hline & & Porcine gelatin \pm thrombin & Surgiflo \pm Evithrom & Ethicon/J\&J, Somerville, NJ, USA \\
\hline & Fibrin & Human pooled plasma liquid & Tisseel & Baxter, Westlake Village, CA, USA \\
\hline & sealant & & Evicel & Ethicon/J\&J, Somerville, NJ, USA \\
\hline & & $\begin{array}{l}\text { Individual human plasma liquid, } \\
\text { bovine collagen, and bovine thrombin }\end{array}$ & Vitagel & Stryker, Malvern, PA, USA \\
\hline & & $\begin{array}{l}\text { Human pooled plasma and equine } \\
\text { collagen patch }\end{array}$ & TachoSil & Baxter, Westlake Village, CA, USA \\
\hline & & $\begin{array}{l}\text { Human pooled plasma and oxidized } \\
\text { regenerated cellulose patch }\end{array}$ & Evarrest & Ethicon/J\&J, Somerville, NJ, USA \\
\hline
\end{tabular}

Abbreviations: $\mathrm{MCH}$, microfibrillar collagen hemostat; J\&J, Johnson and Johnson.

approved patches. The criteria traditionally used to evaluate hemostats include safety, efficacy, usability, and cost. ${ }^{1-4}$ As will be described, the patches represent a major advance in terms of efficacy and usability. Table 2 presents the key characteristic differences of the liquid and patch forms of fibrin sealant in terms of these criteria.

With respect to safety concerns, two of the three liquid products (Tisseel, ${ }^{5}$ Baxter, Westlake Village, CA, USA, and Evicel, ${ }^{6}$ Ethicon/J\&J, Somerville, NJ, USA) and both patch forms of fibrin sealant (TachoSil, ${ }^{7}$ Baxter, and Evarrest, ${ }^{8}$ Ethicon/J\&J) contain human pooled plasma fibrinogen and thrombin. Thus, these materials may be associated with the transmission of viral and/or prion diseases. The risk of human immunodeficiency virus (HIV) and hepatitis appears limited $^{9}$ at this time as a result of donor viral screening, plasma serologic and polymerase testing, and antiviral processing conducted by the manufacturers. ${ }^{5-8}$ However, reports have appeared of parvovirus B19 transmission as a result of pooled plasma fibrin sealant use. ${ }^{10,11}$ The third form of liquid fibrin sealant (Vitagel, Stryker, Malvern, PA, USA) ${ }^{12,13}$ uses individual units of human plasma most often of autologous origin and hence eliminates the risk of human blood-borne disease transmission. On the other hand, this product at present does employ bovine collagen and bovine thrombin and may elicit

Table 2 Comparison of fibrin sealant liquids and patches based on safety, efficacy, usability, and cost

\begin{tabular}{llll}
\hline Formulation & Safety & Efficacy & Usability \\
\hline Fibrin sealant & Human pooled plasma & Fibrinogen and thrombin provide & Sprayable over a large area \\
liquids & $\begin{array}{l}\text { Individual units of } \\
\text { human plasma with } \\
\text { bovine collagen and }\end{array}$ & $\begin{array}{l}\text { Cannot be readily combined } \\
\text { with pressure }\end{array}$ & $\begin{array}{l}\text { Storage in freezer } \\
\text { Preparation improved yet most still require } \\
\text { thrombin }\end{array}$ \\
& & & at least some thawing \\
& Human pooled plasma require plasma donation and processing & May rive \\
Fibrin sealant & Equine collagen & independent activation and clotting & Storage at room temperature \\
& Oxidized regenerated & Can be easily combined with & No preparation required \\
& cellulose & pressure & More \\
\end{tabular}


allergies in those sensitive to proteins of bovine origin as well as an immune-mediated coagulopathy. ${ }^{14}$ The latter occurs in patients developing antibodies to bovine thrombin components that may be associated with a range of abnormalities ranging from laboratory deviations to rare deaths. ${ }^{14}$ The first fibrin sealant patch to be approved by the FDA (TachoSil) uses patch material made of equine collagen, which may be associated with allergic responses in those patients sensitive to horse proteins. The second fibrin sealant patch (Evarrest) ${ }^{8}$ uses a patch of oxidized regenerated cellulose (ORC) and hence avoids any allergic responses in equine collagenallergic patients. The ORC may be associated with the formation of adhesions. It is interesting that the concentrations of fibrinogen and thrombin are higher ${ }^{8}$ in this patch relative to the fibrin sealant equine collagen patch, ${ }^{7}$ possibly needed to overcome a known tendency of the ORC acidic environment to decrease thrombin activity ${ }^{15,16}$ and hence decrease the required conversion of fibrinogen to fibrin.

A possible advantage of both liquid and patch fibrin sealants is that they bring both fibrinogen and thrombin to the bleeding site and do not depend on the blood having adequate levels of fibrinogen to achieve hemostasis. Disseminated intravascular coagulation ${ }^{17}$ as well as acquired ${ }^{18}$ and hereditary hypofibrinogenemia ${ }^{19}$ are a few of the conditions characterized by low or absent levels of fibrinogen in which it would be especially beneficial for a surgical hemostat to contain fibrinogen. The efficacy of both the liquid and patch forms of fibrin sealants has been studied in controlled, multicenter, prospective, randomized, clinical trials. The largest percentages of patients achieving hemostasis after the shortest time intervals following treatments by individual fibrin sealants on an intent-to-treat basis were $90 \%$ at 5 minutes in cardiac procedures for Tisseel, $58 \%$ at 4 minutes in vascular procedures for Evicel, ${ }^{6} 93 \%$ at 3 minutes in cardiac procedures for Vitagel, ${ }^{12} 75 \%$ at 3 minutes in cardiac procedures for TachoSil, ${ }^{7}$ and $98 \%$ at 4 minutes in soft tissue bleeding in abdominal, pelvic, retroperitoneal, and noncardiac thoracic procedures for Evarrest. ${ }^{8}$ Any comparison between these individual agents is difficult for a wide variety of clinical and statistical reasons, including variations in pivotal trial design such as evaluation time points, presence or absence of manual pressure, and numbers of patients enrolled. Also, the severity of baseline bleeding in each eligible patient was not evaluated/published, so the amount of bleeding prior to treatment with fibrin sealant was not presented. The initial degree of bleeding is an important factor in determining product efficacy. In my own fibrin sealant clinical experience (at the University of Virginia, VA, USA, liquid fibrin sealant was placed on porcine gelatin to create a patch prior to FDA approval of the final combination patches), ${ }^{20}$ the ability to combine fibrin sealant with a patch facilitates the use of manual pressure to achieve hemostasis and improves the function of this hemostat, particularly when the degree of bleeding is larger. When using liquid fibrin sealant alone for significant bleeding, however, there is no easy mechanism for applying pressure. This difficulty arises because pressure cannot be easily applied to the liquid without either dislodging the fibrin sealant when removing the article used for applying pressure (eg, mechanical hemostat sponge, gauze sponge, laparotomy pad) or leaving the article permanently in place within the patient. To summarize, it has not been proven on a statistically significantly basis at this time in multicenter, prospective, randomized, clinical trials that fibrin sealant patch efficacy is superior to that of fibrin sealant liquids. However, there would appear to be some apparent advantages in both efficacy and usability that are notable and are expressed in the increased cost of the fibrin sealant patches relative to liquid forms. ${ }^{20}$

In terms of usability, there are two components to consider: methods of application and product preparation. ${ }^{1-4}$ The liquid fibrin sealants have a variety of applicators, including drip and gas-driven spray devices, allowing for local application or delivery over a large area., ${ }^{5,12,13}$ The fibrin sealant patches come in a variety of sizes, and there are some limitations on the amount of patch material to be safely used in one patient. ${ }^{7,8}$ The liquid fibrin sealants are more complex to prepare than the fibrin sealant patches. ${ }^{1-4,20}$ The pooled plasma liquids still require thawing or mixing and/or applicator loading. ${ }^{20}$ One of these liquid fibrin sealant products is now provided frozen and already loaded in its applicator, and in the smallest volume form available $(2 \mathrm{~mL})$ it requires only 10-12 minutes of thawing. ${ }^{5}$ The same product is also provided in freeze-dried powdered form that is storable at room temperature and requires reconstitution and applicator loading. ${ }^{5}$ Another liquid fibrin sealant product requires both thawing and filling of the applicator with fibrinogen and thrombin prior to use. ${ }^{6}$ However, the components of this product may be stored after thawing at room temperature for 24 hours or in a refrigerator for up to 30 days to facilitate more rapid availability at a later time and date. ${ }^{6} \mathrm{~A}$ third liquid fibrin sealant product requires obtaining human plasma, usually from the patient's own blood, followed by loading of one syringe with the patient's platelet-rich or platelet-poor plasma for use with another preprepared syringe containing collagen and bovine thrombin. ${ }^{12,13}$ All of these more complex forms of preparation for liquid fibrin sealants are contrasted 
with the two fibrin sealant patches that are both storable at room temperature and immediately ready upon opening the container. ${ }^{7,8,20}$

The cost of liquid fibrin sealants is relatively high at about $\$ 50 / \mathrm{mL}$ of final delivered material, but the cost of the fibrin sealant patches is even higher, with some reports of patches being as much as $\$ 800$, possibly related to efficacy and usability benefits. ${ }^{20}$

\section{TachoSil}

The FDA approved this commercial product (TachoSil) ${ }^{7}$ consisting of fibrin sealant (fibrinogen $5.5 \mathrm{mg} / \mathrm{cm}^{2}$ and thrombin $2.0 \mathrm{IU} / \mathrm{cm}^{2}$ ) on an equine collagen patch (Figure 1) on April 2, 2010 as an adjunct to hemostasis in cardiovascular surgery. ${ }^{21}$

Its safety profile is related to the use of pooled human plasma-derived fibrinogen and thrombin as well as equine collagen. ${ }^{7,20}$ The pooled plasma may be associated with blood-borne disease transmission of viruses and prions. ${ }^{20}$ Thus, there is a potential risk of HIV, hepatitis A, parvovirus B19, and Creutzfeldt-Jakob disease (CJD) transmission. ${ }^{7}$ Efforts to minimize these risks include donor screening for a high-risk history, serologic and polymerase chain reaction testing, and antiviral processing such as pasteurization, precipitation, adsorption, $\mathrm{pH}$, and gamma irradiation. ${ }^{7}$ There is also a risk of allergic reaction and anaphylaxis in patients sensitive to human or horse proteins, as well as the risk of thromboembolism. ${ }^{7}$ The patch should not be used intravascularly, in the renal pelvis or near the ureter, in between the edges of the skin, in neurosurgery, in closed or infected spaces, or in treating severe or brisk arterial bleeding. ${ }^{7}$ In addition, overpacking of patches should be avoided. ${ }^{7}$ Migration of the patch inside the body is possible. ${ }^{7}$ Exposure of the patch to alcohol, iodine, or heavy metals can inactivate the patch. ${ }^{7}$ There are limitations on the number of patches that should be used in a patient depending on

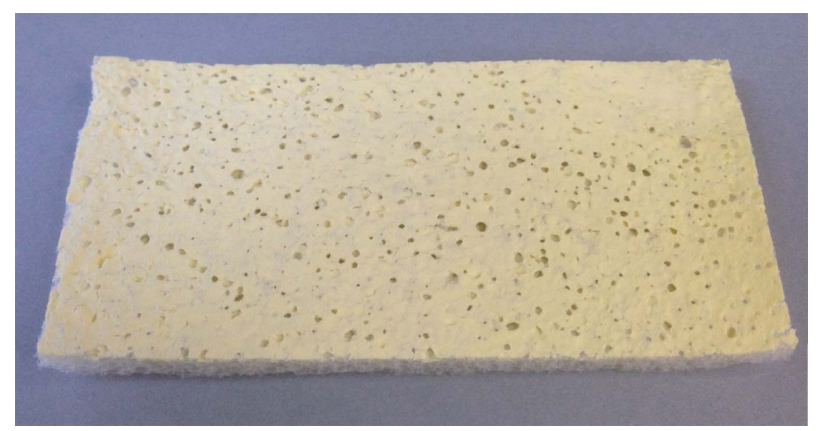

Figure I TachoSil fibrin sealant patch with active yellow side facing upwards. the size of the patch employed: $9.5 \times 4.8 \mathrm{~cm}$ seven or less, $4.8 \times 4.8 \mathrm{~cm} \leq 14$, and $2.5 \times 3.5 \mathrm{~cm} \leq 42 .{ }^{7}$ TachoSil is almost completely biodegraded by 13 weeks. ${ }^{7}$

The product is designed to help immediately stop bleeding by use of pressure on the patch. Hemostasis is then maintained by clot formation as a result of conversion of fibrinogen to fibrin by thrombin forming fibrin sealant as the patch is exposed to blood (the patch may be premoistened with saline (for $\leq 1$ minute). ${ }^{7}$ The patch is capable of withstanding pressure $\leq 46.1 \mathrm{mmHg}^{7}$ In a cardiac surgical clinical trial on an intent-to-treat basis (119 patients), target bleeding sites were treated with TachoSil (59 patients) and a control fleece patch without fibrinogen and thrombin (60 patients). ${ }^{7}$ At 3 minutes, hemostasis was achieved in the TachoSil and control patients in $76.6 \%$ (44/59 patients) and 33.3\% (20/60 patients), respectively $(P<0.0001) .^{7}$ At 6 minutes, hemostasis was achieved in TachoSil and control patients in $94.9 \%$ (56/59 patients) and $71.7 \%$ (43/60 patients), respectively $(P<0.0006)$. $^{7}$

In terms of usability, the yellow (riboflavin) active side is applied to the bleeding site and held in place for $\geq 3$ minutes. $^{7}$ The patch should be placed to extend 1-2 $\mathrm{cm}$ beyond the edge of the wound (or patches may be overlapped in a similar way) and is left in place. ${ }^{7}$ Storage is at room temperature and the product is immediately available after opening the foil pouch. ${ }^{?}$

The cost, as discussed previously, is reportedly about $\$ 800 /$ patch. $^{20}$

\section{Evarrest}

The FDA approved this commercial product, Evarrest (Figure 2), ${ }^{8}$ consisting of fibrin sealant (fibrinogen $7.8 \mathrm{mg} / \mathrm{cm}^{2}$ and thrombin $31.5 \mathrm{IU} / \mathrm{cm}^{2}$ ) embedded in a layer of polyglactin on an ORC patch (Figure 2) on December 5, 2012 as an

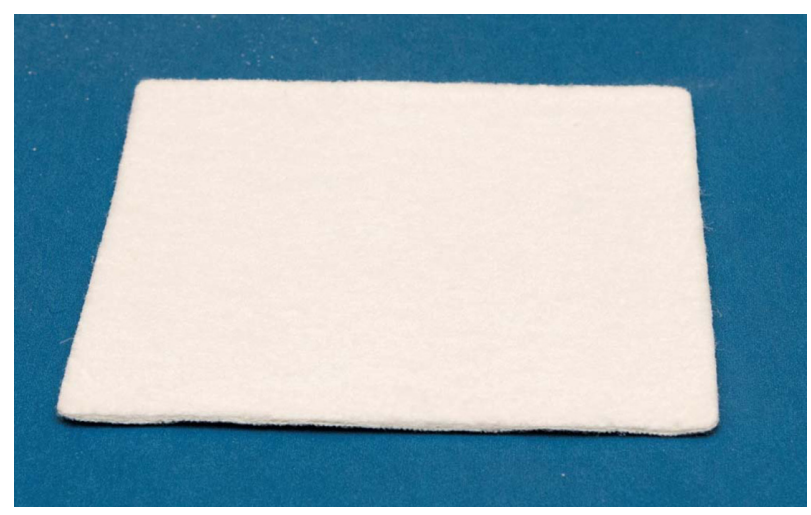

Figure 2 Evarrest fibrin sealant patch with powdery nonembossed active side facing upwards. 
adjunct to hemostasis in soft tissue bleeding at the time of open surgical procedures on the retroperitoneum, abdomen, and pelvis, as well as noncardiac thoracic locations. ${ }^{22}$

Its safety profile is related to the use of pooled human plasma-derived fibrinogen and thrombin as well as ORC. . $^{8,20}$ As with TachoSil, the pooled plasma may be associated with blood-borne disease transmission of viruses, prions, or unknown agents. ${ }^{20}$ Thus, there remains a potential risk of HIV, hepatitis A, parvovirus B19, and CJD transmission. ${ }^{8}$ Efforts to minimize these risks include donor screening for a high-risk history, serologic and polymerase chain reaction testing, and antiviral processing such as pasteurization, solvent/detergent cleansing, and nanofiltration. ${ }^{8}$ There is still a risk of allergic reaction and anaphylaxis in patients sensitive to human but not horse proteins, as well as a risk of thromboembolism. ${ }^{8,20}$ The ORC can adhere to bleeding surfaces and cause adhesions. ${ }^{8}$ The patch should not be used intravascularly; in the renal pelvis or near the ureter; in between the edges of the skin; in neurosurgery; in closed (patch swelling may occur) or infected spaces; in children aged $<1$ month, due to small patient size and limitations on the ease of application; or in treating large defects in visible arteries or veins. ${ }^{8}$ Use of excess material may result in patch migration. ${ }^{8}$ In addition, overpacking of patches, particularly in closed spaces (bony foramina or confines), should be avoided. ${ }^{8}$ The limit on the number of one-size patches $\left(10.2 \times 10.2 \mathrm{~cm}^{2}\right)$ that should be used in a patient is four. ${ }^{8}$ Evarrest is almost completely biodegraded by 8 weeks. ${ }^{8}$

The product is designed to help immediately stop bleeding by use of pressure on the patch. Hemostasis is then maintained by clot formation as a result of conversion of fibrinogen to fibrin by thrombin forming fibrin sealant as the patch is exposed to blood (this patch should not be premoistened). ${ }^{8,20}$ In a clinical trial evaluating soft tissue bleeding occurring during open surgical procedures in multiple specialties, 90 patients were enrolled, with 60 in the Evarrest group and 30 in the control group of ORC alone. ${ }^{8}$ There was a statistically significant $(P<0.0001)$ benefit to using Evarrest compared with ORC (98.3\% [59/60] vs 53.3\% [16/30]) in the proportion of subjects achieving hemostasis at 4 minutes after treatment. ${ }^{8}$

In terms of usability, the powdery active side is applied to the bleeding site (the opposite embossed wavy side is inactive) and held in place for $\geq 3$ minutes. ${ }^{8}$ The patch should extend 1-2 $\mathrm{cm}$ beyond the edge of the wound (or patches may be overlapped in a similar way) and is left in place. ${ }^{8}$ Storage is at room temperature and the product is immediately available after opening the foil pouch. ${ }^{8}$
The cost is anticipated to be similar to that for TachoSil. ${ }^{20}$

\section{Clinical literature review}

Several reviews have recently appeared summarizing the literature in surgical specialties on fibrin sealant patches, including those on TachoSil in multiple, ${ }^{23}$ abdominal, ${ }^{24}$ liver and pancreatic, ${ }^{25}$ and cardiac procedures. ${ }^{26}$ Thus, in this section, only the clinical literature on fibrin sealant patches over the most recent year will be presented. However, to maximize quality and completeness, all the multicenter, prospective, randomized trials on fibrin sealant patches will also be reviewed regardless of publication date.

\section{Liver resection}

As can be seen in Table 3, liver resection was one of the most frequent areas of clinical research with fibrin sealant patches in 2013. Three papers in the last year reported the value of using these patches to treat bleeding following liver procedures. The first was a randomized trial in 45 patients undergoing liver resection at a single institution who received a fibrin sealant patch, ORC, or cyanoacrylate. The investigators found that the fibrin sealant patch group had less rebleeding $(P=0.004)$ after hemostasis (none of 15 patients, $0 \%)$ and less $(P=0.02)$ first day drainage $(150 \pm 60.82 \mathrm{~mL})$ than for ORC (five of 15 patients, $33.3 \%$, and $281 \pm 103.98 \mathrm{~mL}$ ) or cyanoacrylate (two of 15 patients, $13.3 \%$, and $234.66 \pm 187.95 \mathrm{~mL}$ ). They also noted a trend toward more complications in the ORC group compared with the fibrin sealant patch. ${ }^{27}$

In a case report ${ }^{28}$ on the use of a fibrin sealant patch, a patient who anticoagulated with warfarin following cardiac valvular repair required emergency surgery for an actively bleeding liver laceration associated with shock. The patient was treated with a trisegmentectomy by means of total vascular occlusion, endoscopic staplers, and bipolar cautery, as well as fibrin sealant patches, without the need for postoperative transfusions. In another case report, ${ }^{29}$ successful resection of a kidney tumor invading the liver was facilitated using fibrin sealant patches to reduce bleeding from the liver and vena cava.

Table 3 The most frequent areas of fibrin sealant patch clinical research in 2013

Most frequent topics of recent fibrin sealant patch clinical research

Liver resection bleeding

Lymphatic leakage

Lung air leaks 
There are three other multicenter, prospective, randomized trials in the literature involving the use of fibrin sealant patches for liver resections. In the first, fibrin sealant patches were compared with argon beam coagulator for achieving hemostasis at the cut edge of the liver following liver resection. ${ }^{30}$ Mean time to hemostasis was shorter for the fibrin sealant patch (3.9 minutes vs 6.3 minutes, $P=0.0007$ ), and hemoglobin concentration in the drainage fluid was less in patch patients $(1.1 \mathrm{mmoles} / \mathrm{L}$ vs $2.3 \mathrm{mmoles} / \mathrm{L}, P=0.012)$ as compared with patients treated with the argon beam coagulator. Adverse events were similar in both groups. Another similar multicenter, prospective, randomized trial ${ }^{31}$ also found shorter time to hemostasis for the fibrin sealant patches as compared with the argon beam coagulator in liver resection (3.6 minutes vs 5.0 minutes, $P=0.0018$ ) but no differences in postoperative drainage parameters. Adverse events were also similar in both groups. Finally, a recent multicenter, prospective, randomized trial compared a patch composed of polyethylene glycol polymer and ORC with a fibrin sealant patch ${ }^{32}$ and found a shorter time to hemostasis for the polyethylene glycol patch ( 1 minute vs 3 minutes, $P<0.001)$ compared with the fibrin sealant patch independent of target site bleeding severity or size.

\section{Lymphatic drainage}

Two recent single-center studies reported no clear significant benefit to using fibrin sealant patches to reduce the degree of seroma accumulation following axillary dissection. One found that comparing the use of drains $(\mathrm{N}=20)$ versus the use of fibrin sealant patches without drains using historical controls $(\mathrm{N}=20)$ revealed a larger initial seroma rate in the patch group $(P=0.0194)$ but a significant 48 -hour reduction in the length of hospitalization $(P=0.002) .{ }^{33}$ The second retrospective case-controlled study revealed no benefit to using fibrin sealant patches in terms of postoperative drainage volume or persistence. ${ }^{34}$ In addition, the fibrin sealant patch cases had significantly longer hospitalizations (5.0 \pm 1.6 days vs $3.1 \pm 1.8$ days, $P=0.006$ ).

Two other reports of single-center trials using fibrin sealant patches also appeared. One used fibrin sealant patches to reduce lymphocele formation following laparoscopic pelvic lymphadenectomy and found using historical case controls that there was a significant benefit to using the patches in terms of reducing drainage volume $(65 \pm 15 \mathrm{~mL}$ vs $150 \pm 40$ $\mathrm{mL}, P<0.01)$, day of drain removal $(2 \pm 0.5$ days vs $3 \pm 0.5$ days, $P<0.01$ ), and incidence of lymphocele formation (five patients versus 15 patients, $P<0.05$ ) but no significant benefit at reducing lymphocele-related symptoms (two patients vs five patients, $P=0.4264$, not significant).$^{35}$ In another case-controlled, single-center study, patients with lymphorrhea following vascular surgery were found to have benefit to using fibrin sealant patches compared with closed suction drainage in terms of the time with persistent drainage (4.87 days less) and length of hospitalization (3.88 days less), although no statistical comparisons were provided in the paper. ${ }^{36}$

\section{Lung resection}

In a single-center, prospective trial, patients with air leaks at the time of reoperative lung surgery were randomized to receive either a fibrin sealant patch or additional stapling/ suturing to treat persistent intraoperative air leakage. The fibrin sealant patch group had significantly shorter duration of the operation ( 3.6 hours vs 4.0 hours, $P=0.023$ ), air leaks (4.7 days vs 10.0 days, $P<0.001$ ), and first and second chest tube time to drain removal ( 3.8 days vs 5.5 days, $P=0.005$, and 6.1 days vs 10.8 days, $P<0.001$, respectively). Also, the patch group had fewer persistent ( $\geq 9$ days) air leaks (one patient vs seven patients, $P=0.008$ ) ${ }^{37}$ In a multicenter, prospective, randomized trial on patients undergoing lung resection, the use of fibrin sealant patches was compared with standard of care for air leak control at the time of the first surgical intervention. A significant reduction in postoperative air leak duration $(P=0.0437)$ was noted, but no significant benefits on duration of chest tube drainage or adverse events were discovered..$^{38}$ Finally, in an older multicenter, prospective, randomized trial, patients were again treated for air leakage with fibrin sealant patches or standard of care. Significant reductions in intraoperative air leakage $(P=0.042)$ and duration of postoperative air leakage $(P=0.030)$ were reported, with a shortening in the time to chest tube removal approaching statistical significance $(P=0.054) .{ }^{39}$

\section{Cardiovascular}

A series of 12 cases reported from Germany supports the use of a sandwich consisting of a single folded-over patch or back-to-back fibrin sealant patches inserted between the dissected layers of the aorta in acute dissections as a means of assuring tissue management and minimizing bleeding so that the use of a potentially destructive sealant can be avoided. ${ }^{40}$ The authors suggest that they achieved a low mortality ( $8.3 \%$ ), no neurologic events, $13.6 \pm 6$ days of intensive care unit stay, $20.7 \pm 4.4$ days of hospital stay, low transfusion and coagulation product use $(7.0 \pm 2.6$ red blood cells, $3.4 \pm 1.5$ platelets, and $8.0 \pm 4.3$ fresh frozen plasma) with no redissections or valvular insufficiency 
in follow-up of 1 year (computed tomography scans and echocardiography).

A multicenter, prospective, randomized, European trial of fibrin sealant patch versus fleece for treatment of mild to severe venous or arterial bleeding from the heart or aorta showed statistically significant benefit to using fibrin sealant at achieving hemostasis, favoring the patch at 3 minutes (75\%, 95\% confidence interval [CI]: $0.64-0.86$ vs $33 \%$, CI $0.21-0.45, P<0.0001)$ and 6 minutes (95\%, CI: $0.89-1.0$ vs $72 \%$, CI: $0.60-0.83, P<0.0006) .{ }^{41}$ The incidence of adverse events was similar in both groups.

\section{Head and neck}

A report of three cases appeared, two following laryngectomy and the other following a lateral pharyngotomy, suggesting that conservative treatment of a pharyngocutaneous fistula using fibrin sealant patches can be used to successfully facilitate a more rapid recovery, particularly in the setting of previous irradiation and the need for early additional chemotherapy as treatment for a malignancy. ${ }^{42}$ One patient had transoral placement of a patch, and the other two had reoperations with patch placement to facilitate sutured tissue repairs of the fistulas.

\section{Inguinal hernia repair}

A series of 52 patients had classic open Lichtenstein inguinal hernia repairs using fibrin sealant patches without sutures and were compared with 45 patients treated with standard polypropylene mesh. ${ }^{43}$ The fibrin sealant patch group suffered no recurrences in 3 years of follow-up. The authors suggested that there was also less postoperative pain and pain medications used, as well as fewer complications, in the fibrin sealant patch group.

\section{Ophthalmology}

A case report of two patients undergoing treatment of corneal macroperforations described successfully using fibrin sealant patches in combination with bovine pericardial patches to close the defects with maintenance of visual acuity. ${ }^{44}$

\section{Pancreatic resection}

A multicenter, prospective, randomized, European trial of 275 patients found no benefit to using fibrin sealant patches in decreasing the incidence of postoperative pancreatic fistulas (fibrin sealant patches, 62\%; standard of care $68 \%$; $P=0.267) .{ }^{45}$ The amount of amylase in the drainage fluid was significantly reduced $(P=0.025)$ in the fibrin sealant patch patients.

\section{Renal resection}

A case report of three pediatric patients undergoing nephronsparing surgery for Wilms tumor suggested that the use of fibrin sealant patches could help achieve successful hemostasis in the remaining renal tissue following closure of the collecting system. ${ }^{46}$ In a multicenter, prospective, randomized trial of 185 adult patients undergoing nephronsparing surgery, fibrin sealant patch time to hemostasis was compared with standard suturing and found to have significant improvement in time to hemostasis (mean: 5.3 minutes vs 9.5 minutes, $P<0.0001) .{ }^{47}$ In addition, patch patients achieved hemostasis at 10 minutes $92 \%$ of the time while sutured patients achieved hemostasis $67 \%$ of the time $(P<0.0001)$. No significant differences in the occurrence of adverse events were discovered.

\section{Spine}

A case report appeared in which fibrin sealant patches were used to repair dural cerebrospinal fluid hygromas occurring following anterior thoracic spine approaches with successful resolution of cranial nerve palsy. ${ }^{48}$

\section{Urology}

Treatment of stable Peyronie's disease with advanced penile deviation was undertaken in a series of 70 consecutive patients treated with partial plaque excision and placement of a fibrin sealant patch. ${ }^{49}$ The authors suggested that the method results in decreased operative times and fewer postoperative hematomas.

\section{Summary}

Fibrin sealant patches appear to be a safe, effective, and easy-to-use addition to the surgeon's toolbox of hemostats, sealants, and adhesives. Multicenter, prospective, randomized trials support its effectiveness as a hemostat, with recent literature also supporting its role as a tissue sealant and mechanical barrier. These patches appear to be important new additions to the surgical toolbox.

\section{Disclosure}

There are or have been recent consulting agreements for the services of the author between the University of Virginia and Baxter, Bayer, BioLineRx, Biom'Up, Cadence, Covidien, Cubist, Ethicon/J\&J, Grifols, Lifebond, Luna Innovations, Medafor, Medicines Company, Neomend, Profibrix, SEAlantis, and Zymogenetics/BMS. Dr Spotnitz also has a part-time position as the Chief Medical Officer of Biom'Up. The author reports no other conflicts of interest in this work. 


\section{References}

1. Spotnitz WD, Burks S. Hemostats, sealants, and adhesives: components of the surgical toolbox. Transfusion. 2008;48:1502-1516.

2. Spotnitz WD, Burks S. State-of-the-art review: hemostats, sealants, and adhesives. II: Update as well as how and when to use the components of the surgical toolbox. Clin Appl Thromb Hemost. 2010;16: 497-514.

3. Spotnitz WD, Burks S. Hemostats, sealants, and adhesives. III: A new update as well as cost and regulatory considerations for components of the surgical toolbox. Transfusion. 2012;52:2243-2255.

4. Spotnitz WD. Hemostats, sealants, and adhesives: a practical guide for the surgeon. Am Surg. 2012;78:1305-1321.

5. Tisseel [package insert]. Westlake Village, CA: Baxter; 2012.

6. Evicel [package insert]. Somerville, NJ: Johnson and Johnson; 2007.

7. TachoSil [package insert]. Westlake Village, CA: Baxter; 2010.

8. Evarrest [package insert]. Somerville, NJ: Ethicon/J\&J; 2012.

9. Joch C. The safety of fibrin sealants. Cardiovasc Surg. 2003; 11(Suppl 1):23-28.

10. Hino M, Ishiko O, Honda KI, et al. Transmission of symptomatic parvovirus B19 infection by fibrin sealant used during surgery. $\mathrm{Br} J$ Haematol. 2000;108:194-195.

11. Kawamura M, Sawafuji M, Watanabe M, Horinouchi H, Kobayashi K. Frequency of transmission of human parvovirus B19 infection by fibrin sealant used during thoracic surgery. Ann Thorac Surg. 2002;73: 1098-1100.

12. Vitagel [package insert]. Malvern, PA: Stryker; 2006.

13. Vitagel [product brochure]. 5703-0014 rev. 02. Malvern, PA: Stryker; 2012.

14. Thrombin JMI [package insert]. New York, NY: King/Pfizer/UPM Pharmaceuticals; 2011.

15. Surgicel, Surgicel Fibrillar, and Surgicel Nu-Knit [package insert]. Somerville, NJ: Ethicon/J\&J; 2005.

16. De Robertis E, Kozek-Langenecker S, Tufano R, Romano GM, Piazza O, Zito Marinosci G. Coagulopathy induced by acidosis, hypothermia and hypocalcaemia in severe bleeding. Minerva Anestesiol. Epub March 7, 2014.

17. Counts RB, Haisch C, Simon TL, Maxwell NG, Heimbach DM, Carrico CJ. Hemostasis in massively transfused trauma patients. Ann Surg. 1979;190(1):91-99.

18. Maung AA, Kaplan LJ. Role of fibrinogen in massive injury. Minerva Anestesiol. 2014;80:89-95.

19. Peyvandi F. Epidemiology and treatment of congenital fibrinogen deficiency. Thromb Res. 2012;130(Suppl)2:S7-S11.

20. Spotnitz WD. Fibrin sealant: the only approved hemostat, sealant, and adhesive: a laboratory and clinical perspective. ISRN Surg. 2014;2014:203943.

21. FDA approval letter for TachoSil (Nycomed), April 2, 2010.

22. FDA approval letter for Evarrest (Ethicon/J\&J), December 5, 2012.

23. Rickenbacher A, Breitenstein S, Lesurtel M, Frilling A. Efficacy of TachoSil a fibrin-based haemostat in different fields of surgery: a systematic review. Expert Opin Biol Ther. 2009;9:897-907.

24. Toro A, Mannino M, Reale G, Di Carlo I. TachoSil use in abdominal surgery: a review. J Blood Med. 2011;2:31-36.

25. Simo KA, Hanna EM, Imagawa DK, Iannitti DA. Hemostatic agents in hepatobiliary and pancreas surgery: a review of the literature and critical evaluation of a novel carrier-bound fibrin sealant (TachoSil). ISRN Surg. 2012;2012:729086.

26. Rousou JA. Use of fibrin sealants in cardiovascular surgery: a systematic review. J Card Surg. 2013;28:238-247.

27. Kakaei F, Seyyed Sadeghi MS, Sanei B, Hashemzadeh S, Habibzadeh A. A randomized clinical trial comparing the effect of different haemostatic agents for haemostasis of the liver after hepatic resection. HPB Surg. 2013;2013:587608.

28. Kutlutürk K, Soyer V, Dirican A, et al. Case report: emergency liver resection with staplers for spontaneous liver haemorrhage in a patient receiving anticoagulant therapy. Case Rep Med. 2013;2013:204046.
29. Drewniak T, Rzepecki M, Juszczak K, Jakubowski J, Sandheim M, Maciukiewicz P. [The use of hemostatic agent TachoSil in surgical treatment of kidney cancer infiltrating liver: case report]. Pol Merkur Lekarski. 2013;34:345-347. Polish.

30. Frilling A, Stavrou GA, Mischinger H-J, et al. Effectiveness of a new carrier-bound fibrin sealant versus argon beamer as haemostatic agent during liver resection: a randomized prospective trial. Langenbecks Arch Surg. 2005;390:114-120.

31. Fischer L, Seiler CM, Broelsch CE, et al. Hemostatic efficacy of TachoSil in liver resection compared with argon beam coagulator treatment: an open, randomized, prospective, multicenter, parallel-group trial. Surgery. 2011;149:48-55.

32. Öllinger R, Mihaljevic AL, Schuhmacher C, et al. A multicentre, randomized clinical trial comparing the Veriset ${ }^{\mathrm{TM}}$ haemostatic patch with fibrin sealant for the management of bleeding during hepatic surgery. HPB (Oxford). 2013;15:548-558.

33. Lacoste C, Ouldamer L, Body G, Marret H. [Does the use of TachoSil allow to reduce the morbidity of axillary dissection?]. Gynecol Obstet Fertil. 2013;41:141-143. French.

34. Vinchant $M$, Bonneau $C$, Lesavre $M$, et al. Interest of a thrombin and fibrinogen combipatch in preventing breast cancer seroma after lymph node dissection. Gynecol Obstet Fertil. 2013;41:583-587. French.

35. Tinelli A, Mynbaev OA, Tsin DA, et al. Lymphocele prevention after pelvic laparoscopic lymphadenectomy by a collagen patch coated with human coagulation factors: a matched case-control study. Int J Gynecol Cancer. 2013;23:956-963.

36. Ilzecki M, Zubilewicz T, Przywara S, Terlecki P. The evaluation of the effectiveness of TachoSil in the treatment of lymphorrhea of the postoperative wound in the selected group of patients, after vascular reconstructive surgeries: preliminary report. Polski Przeglad Chirurgiczny. 2013;85:687-692.

37. Filosso PL, Ruffini E, Sandri A, Lausi PO, Giobbe R, Oliaro A. Efficacy and safety of human fibrinogen-thrombin patch $\left(\mathrm{TachoSil}^{\mathbb{R}}\right)$ in the treatment of postoperative air leakage in patients submitted to redo surgery for lung malignancies: a randomized trial. Interact Cardiovasc Thorac Surg. 2013;16:661-666.

38. Lopez C, Facciolo F, Lequaglie C, et al. Efficacy and safety of fibrin sealant patch in the treatment of air leakage in thoracic surgery. Minerva Chir. 2013;68:559-567.

39. Marta GM, Facciolo F, Ladegaard L, et al. Efficacy and safety of TachoSil $^{\circledR}$ versus standard treatment of air leakage after pulmonary lobectomy. Eur J Cardiothorac Surg. 2010;38:683-689.

40. Lisy M, Kahlil M, Stock UA, Wildhirt SM. Fibrin sealant patch for repair of acute type A aortic dissection. J Card Surg. 2013;28: 736-741.

41. Maisano F, Kjaergård HK, Bauernschmitt R, et al. TachoSil surgical patch versus conventional haemostatic fleece material for control of bleeding in cardiovascular surgery: a randomised controlled trial. Eur J Cardiothorac Surg. 2009;36:708-714.

42. Weiss BG, Ihler F, Matthias C, Canis M. Coated collagen patches for closure of pharyngo-cutaneous fistulas. Amer J Otolarng. 2014;35: 246-250.

43. Arslani N, Gajzer B, Papeš D, et al. A new approach for transversalis fascia reinforcement in Lichtenstein's inguinal hernia repair. Surg Today. 2013;43:211-214.

44. Feliciano-Sánchez A, García-Gil R. Non-infectious corneal macroperforations treated with a combination of TachoSil ${ }^{\circledR}$ and Tutopach ${ }^{\circledR}$. A report of 2 cases. Arch Soc Esp Oftalmol. 2014;89(6):250-253.

45. Montorsi M, Zerbi A, Bassi C, Capussotti L, Coppola R, Sacchi M; Italian TachoSil Study Group. Efficacy of an absorbable fibrin sealant patch (TachoSil) after distal pancreatectomy: a multicenter, randomized, controlled trial. Ann Surg. 2012;256:853-859.

46. Mele E, Ceccanti S, Schiavetti A, Bosco S, Masselli G, Cozzi DA. The use of TachoSil ${ }^{\mathbb{R}}$ as hemostatic sealant in nephron sparing surgery for Wilms tumor: preliminary observations. J Ped Surg. 2013;48: 689-694. 
47. Siemer S, Lahme S, Altziebler S, et al. Efficacy and safety of TachoSil as haemostatic treatment versus standard suturing in kidney tumour resection: a randomised prospective study. Eur Urol. 2007;52: 1156-1163.

48. Khurana A, Brousil J, Russo A, Evans A, Quraishi NA, Boszczyk BM. Intracranial hypotension with a sixth cranial nerve palsy subsequent to massive thoracic CSF hygroma: a rare complication of thoracic disc excision. Eur Spine J. 2013;22:2047-2054.
49. Hatzichristodoulou G, Gschwend JE, Lahme S. Surgical therapy of Peyronie's disease by partial plaque excision and grafting with collagen fleece: feasibility study of a new technique. Internat J Impotence Res. 2013;25:183-187.

Open Access Surgery

\section{Publish your work in this journal}

Open Access Surgery is an international, peer-reviewed, open access journal that focuses on all aspects of surgical procedures and interventions. Patient care around the peri-operative period and patient outcomes post surgery are key topics. All grades of surgery from minor cosmetic interventions to major surgical procedures are covered. Novel techniques

Submit your manuscript here: http://www.dovepress.com/open-access-surgery-journal

\section{Dovepress}

and the utilization of new instruments and materials, including implants and prostheses that optimize outcomes constitute major areas of interest. The manuscript management system is completely online and includes a very quick and fair peer-review system. Visit http://www.dovepress.com/ testimonials.php to read real quotes from published authors. 